\title{
Diversidade genética por marcadores moleculares em Fusarium oxysporum f. sp. cubense no Estado de Santa Catarina
}

\author{
Genetic diversity by molecular markers in Fusarium oxysporum f. sp. cubense in \\ Santa Catarina State
}

\author{
Cristiane Maria da Silva ${ }^{I^{*}}$ Robert Harri Hinz $^{\text {II }}$ Marciel João Stadnik ${ }^{1}$ \\ Adriana Pereira ${ }^{\mathrm{II}}$ Fernando Adami Tcacenco ${ }^{\mathrm{II}}$
}

\section{RESUMO}

O mal-do-panamá, causado por Fusarium oxysporum $f$. sp. cubense (FOC), é um dos principais problemas fitossanitários da bananicultura. $O$ uso de cultivares resistentes é o método preferencialmente recomendado para o seu controle, sendo a avaliação da diversidade genética do patógeno necessária no desenvolvimento de estratégias de manejo da doença a longo prazo. Assim, este trabalho teve como objetivo estudar a variabilidade genética de isolados de FOC por marcadores moleculares RAPD e SSR. Foram avaliados 64 isolados coletados em regiões produtoras do estado de Santa Catarina, sendo que $100 \%$ deles foram patogênicos à bananeira da cv. 'Enxerto'. As análises de conglomerados com esses marcadores revelaram variabilidade entre os isolados amostrados. As técnicas moleculares aplicadas foram eficientes em separar os isolados em três grupos distintos. Os membros de cada grupo, em cada uma das técnicas, em geral, foram coincidentes e três dos isolados (CO16, JS23 e JS26) apresentaram-se mais distantes geneticamente nos dendrogramas de similaridade.

Palavras-chave: banana, doença, fungo, RAPD, SSR.

\section{ABSTRACT}

Panama disease, caused by Fusarium oxysporum f. sp. cubense (FOC), is one of the major disease of banana crop. The use of resistant cultivars is the recommended control method, but the assessment of the pathogen genetic diversity is necessary for the development of long-term management strategies. This study aimed to analyze the genetic variability of isolates of FOC in Santa Catarina state, using RAPD and SSR molecular markers. It was evaluated 64 isolates collected in the producing regions of Santa Catarina state, where 100\% of them were pathogenic to banana cv. 'Enxerto'. Cluster analysis by molecular markers revealed variability among the isolates. Both molecular techniques were effective in separating the isolates into tree distinct groups and, in general, led to similar grouping. Three isolates (CO16, JS23 and JS26) were genetically more distant in dendograms of similarity.

Key words: banana, disease, fungi, RAPD, SSR.

\section{INTRODUÇÃO}

O mal-do-panamá, causado por Fusarium oxysporum f. sp. cubense (FOC), é uma doença endêmica em todas as regiões produtoras de banana, sendo citado como uma das seis mais importantes doenças de plantas cultivadas e responsável por grandes perdas econômicas (PLOETZ, 2006). O fungo infecta as cultivares dos subgrupos Prata e Cavendish (GROENEWALD et al., 2006), causando a morte das plantas e dificultando ou, até mesmo, impedindo a implantação de novos plantios, uma vez que este pode sobreviver no solo durante muitos anos (CORDEIRO \& MATOS, 2005).

Entre as poucas opções para o controle do mal-do-panamá, destaca-se o uso de variedades resistentes (PLOETZ, 2006). Contudo, a seleção de genótipos resistentes ou tolerantes é um processo caro, longo e trabalhoso (ASIF et al., 2004), pois os resultados necessitam ser confirmados por vários ciclos de seleção.

'Programa de Pós-graduação em Recursos Genéticos Vegetais, Departamento de Fitotecnia, Universidade Federal de Santa Catarina (UFSC), Rodovia Admar Gonzaga, 1346, 88034-001, Florianópolis, SC, Brasil. E-mail: crisfito@hotmail.com. *Autor para correspondência.

"Empresa de Pesquisa Agropecuária e Extensão Rural de Santa Catarina (Epagri), Estação Experimental de Itajaí, Itajaí, SC, Brasil. 
A habilidade de adaptação do patógeno, bem como a presença de novos genótipos patogênicos, pode tornar a resistência uma solução temporária (SUTTON, 2000). Portanto, é importante conhecer as raças e/ou patotipos predominantes e a dinâmica de populações para auxiliar nos programas de melhoramento. Além disso, a avaliação da diversidade genética do patógeno é requerida para o desenvolvimento de estratégias de manejo a longo prazo (KUMAR et al., 2006).

Técnicas moleculares como RAPD (polimorfismo de DNA amplificados ao acaso) e SSR (sequências simples repetidas, ou microssatélites) têm contribuído nos estudos de variabilidade de Fusarium oxysporum (BELABID et al., 2004; BOGALE et al., 2005; GROENEWALD et al., 2006; DUTECH et al., 2007). A técnica RAPD, que utiliza um único iniciador com sequência arbitrária para amplificar regiões aleatórias do genoma, apresenta a vantagem de ter baixo custo. Os microssatélites, por sua vez, são regiões do genoma que possuem repetições em cadeia, e as sequências de DNA que flanqueiam os microssatélites são geralmente conservadas entre os indivíduos de uma mesma espécie, ou até mesmo entre espécies relacionadas (DUTECH et al., 2007). Essa técnica vem sendo também utilizada com sucesso no estudo de diversidade em Fusarium oxysporum (BOGALE et al., 2005).

O objetivo deste trabalho foi estudar a variabilidade genética de isolados de $F O C$ em bananais de nove municípios catarinenses, por meio de marcadores moleculares RAPD e SSR.

\section{MATERIAL E MÉTODOS}

Foram coletadas 64 amostras de rizoma de bananeiras adultas da cv. 'Enxerto' com sintomas do mal-do-panamá. As coletas foram feitas em nove municípios catarinenses: Luis Alves - LA (10 bananais); Corupá - CO, Jaraguá do Sul - JS, Jacinto Machado JM e Santa Rosa do Sul - SR (oito bananais em cada município); Schroeder - SH (sete bananais); Massaranduba - MA e Siderópolis - SI (seis bananais em cada município); e São João do Itaperiú - SJ (três bananais). O pseudocaule foi cortado próximo à inserção do rizoma, retirando-se em seguida aproximadamente $300 \mathrm{~g}$ da área sintomática. O material coletado foi tratado com hipoclorito de sódio (1\%) por 10 minutos e os fragmentos infectados foram transferidos para placas de Petri, contendo meio de cultura BDA (Batata, Dextrose e Agar) e incubados por sete dias a $25^{\circ} \mathrm{C}$ sob luz contínua. A confirmação da espécie foi feita pela observação das estruturas reprodutivas do patógeno (NELSON et al., 1983). Para confirmação da patogenicidade dos isolados, mudas de bananeira 'Enxerto' com 12 semanas de idade foram inoculadas por meio da técnica de imersão do sistema radicular das plantas em uma suspensão de $10^{6}$ conídios (CASTRO et al., 2008). A avaliação foi realizada 35 dias após a inoculação, observando-se o desenvolvimento de sintomas típicos do mal-do-panamá (VENTURA \& HINZ, 2002).

Para obtenção de DNA fúngico, os isolados foram transferidos para meio BDE (Batata, Dextrose, Extrato de Levedura) e incubados por sete dias a $25^{\circ} \mathrm{C}$ sob agitação contínua. Após esse período, a massa micelial de cada isolado foi filtrada e seca por duas horas em câmara de fluxo laminar. Um grama da massa micelial foi macerado com nitrogênio líquido e transferido para cápsulas de plástico do tipo Ependorf de $2 \mathrm{~mL}$. Em seguida, o DNA foi extraído com $4,1 \%$ de SDS, conforme metodologia de SCOTT et al. (1993). Além das 64 amostras coletadas, dois isolados do Banco de Cepas da Epagri/EEI (Pyricularia grisea e Fusarium graminearum) foram incluídos na avaliação e serviram como controle negativo. A qualidade do DNA foi verificada em gel de agarose $0,8 \%$ corado com brometo de etídeo $\left(5 \mu \mathrm{g} \mathrm{mL}^{-1}\right)$ e a sua quantificação foi feita por espectrofotometria a $260 \mathrm{~nm}$.

Foram testados 29 iniciadores RAPD anteriormente definidos por VAKALOUNAKIS \& FRAGKIADAKIS (1999), MOSTAFA et al. (2002) e MARTINS (2005). As reações de PCR foram realizadas em duplicata em volume de $25 \mu \mathrm{L}$ contendo tampão PCR (1X), $2 \mathrm{mM} \mathrm{MgCl}_{2}, 0,25 \mathrm{mM}$ dNTP, $0,4 \mu \mathrm{M}$ de iniciadores, 20ng de DNA molde e 1U de Taq DNA polimerase. As reações de amplificação foram realizadas conforme MARTINS (2005). Os produtos da amplificação foram separados por eletroforese em gel de agarose $1,5 \%$ a $60 \mathrm{v}$, durante quatro horas e, posteriormente, tratados com brometo de etídeo $\left(5 \mu \mathrm{g} \mathrm{mL}^{-1}\right)$, visualizados em transluminador de luz ultravioleta e fotografados. Foram também testados seis iniciadores SSR (MB2, MB5, MB9, MB11, MB13, MB17) desenvolvidos para Fusarium oxysporum por BOGALE et al. (2005). As reações de PCR foram realizadas em duplicata em volume de $25 \mu \mathrm{L}$ contendo tampão PCR (1X), 2,5 $\mathrm{mM} \mathrm{MgCl}_{2}$, $0,25 \mathrm{mM}$ dNTP, $0,2 \mu \mathrm{M}$ de cada iniciador, $20 \mathrm{ng}$ de DNA molde e 1,25U de Taq DNA polimerase. As reações de amplificação foram realizadas conforme BOGALE et al. (2005), sendo as temperaturas de anelamento específicas para cada iniciador. Os produtos resultantes da amplificação foram separados por eletroforese vertical em géis de poliacrilamida $6 \%, 45 \mathrm{w}$ e 3000v. Os fragmentos amplificados foram corados com nitrato de prata segundo metodologia de KOPP (2005).

Os resultados das amplificações foram codificados na forma de uma matriz binária $(0=$ ausentes 
e 1=presentes). A relação entre os indivíduos foi medida pelo coeficiente de similaridade de Jaccard e o agrupamento dos indivíduos foi feito por análise de conglomerados, utilizando o método hierárquico aglomerativo UPGMA (Agrupamento por médias não ponderadas), resultando em um dendrograma. $\mathrm{O}$ programa utilizado para a análise foi o NTSYS-PC 2.1 (ROHLF, 2000).

\section{RESULTADOS E DISCUSSÃO}

Dez dos 29 iniciadores de RAPD testados apresentaram padrões de amplificação bem definidos e, por isso, foram utilizados nas análises. Eles amplificaram 99 fragmentos, sendo 81 polimórficos. O tamanho dos fragmentos variou de 0,25 a $2,2 \mathrm{~Kb}$. Os iniciadores que amplificaram o maior número de bandas polimórficas foram R1 e R3 e os que amplificaram o menor número foram OPB $03 \mathrm{e} \mathrm{OPF} 05$ (Tabela 1 e Figura 1A). A análise de conglomerados na qual foram incluídos $\boldsymbol{P}$. grisea e $\boldsymbol{F}$. graminearum indicou que esses dois isolados apresentaram uma similaridade de apenas $20 \%$ em relação aos demais (resultados não mostrados), mostrando-se, portanto, adequados como controles. Os resultados da análise de conglomerados na qual os controles foram excluídos encontram-se na Figura 2A. Observou-se a formação de um grupo de 58 indivíduos com alta similaridade, sendo que 30 deles apresentaram similaridade interna de $100 \%$ e os demais apresentaram similaridade entre $90 \%$ e $98 \%$. Um segundo grupo, composto por três isolados (SJ19, JS25 e JS28), apresentou um alto nível interno de similaridade interna (95\%), mas uma similaridade de apenas $84 \%$ com o grupo anterior. Os demais isolados (CO16, JS23 e JS26) apresentaram uma menor similaridade entre si $(75 \%)$ e

Tabela 1 - Sequência de iniciadores usados nas reações de RAPD, com o número total de fragmentos utilizados para determinar a similaridade genética entre os isolados de Fusarium oxysporum f. sp. cubense.

\begin{tabular}{lccc}
\hline $\begin{array}{l}\text { Identificaçao } \\
\text { dos iniciadores }\end{array}$ & \multicolumn{1}{c}{ Sequência } & $\begin{array}{c}\text { Número de } \\
\text { fragmentos } \\
\text { amplificados }\end{array}$ & $\begin{array}{c}\text { Número de } \\
\text { fragmentos } \\
\text { polimórficos }\end{array}$ \\
\hline OPAX 10 & 5'-CCAGGCTGAC-3' & 10 & 07 \\
OPAX 12 & 5'-GGTCGGGTCA-3' & 08 & 08 \\
OPP 16 & 5'-CCAAGCTGCC-3' & 06 & 06 \\
174 & 5'-ACGATCGCGG-3' & 14 & 13 \\
R1 & 5'-CGGCCACCCT-3' & 20 & 17 \\
R3 & 5'-CGGCCACCCT-3' & 18 & 16 \\
PU 2 & 5'-ACGGATCCTG-3' & 08 & 05 \\
OPB 03 & 5'-CATCCCCCTG-3' & 02 & 01 \\
OPB 04 & 5'-GGACTGGAGT-3' & 05 & 05 \\
OPF 05 & 5'-CCGAATTCCC-3' & 08 & 03 \\
TOTAL & & 99 & 81 \\
\hline
\end{tabular}

uma similaridade de apenas $45 \%$ com os outros dois grupos.

O uso da técnica RAPD no estudo de populações de Fusarium vem sendo relatado como uma ferramenta potencial para analisar a variabilidade genética. Por exemplo, BUSSO et al. (2007) utilizaram oito iniciadores para a caracterização molecular de $\boldsymbol{F}$. graminearum, obtendo dois grupos distintos. KURAMAE \& SOUZA (2002) estimaram a variabilidade genética entre quatro formae speciales de $\boldsymbol{F}$. oxysporum e concluíram que apenas dez iniciadores RAPD, os quais geraram 68 bandas polimórficas, são suficientes para diferenciar os isolados de diferentes hospedeiros. PARK et al. (2006), também utilizando dez marcadores RAPD para analisar formae speciales de $\boldsymbol{F}$. oxysporum, concluíram que esse é um bom marcador para estudo de diversidade genética. Resultados semelhantes foram obtidos por VAKALOUNAKIS \& FRAGKIADAKIS (1999), MOSTAFA et al. (2002) e BELABID et al. (2004), indicando ser o RAPD uma

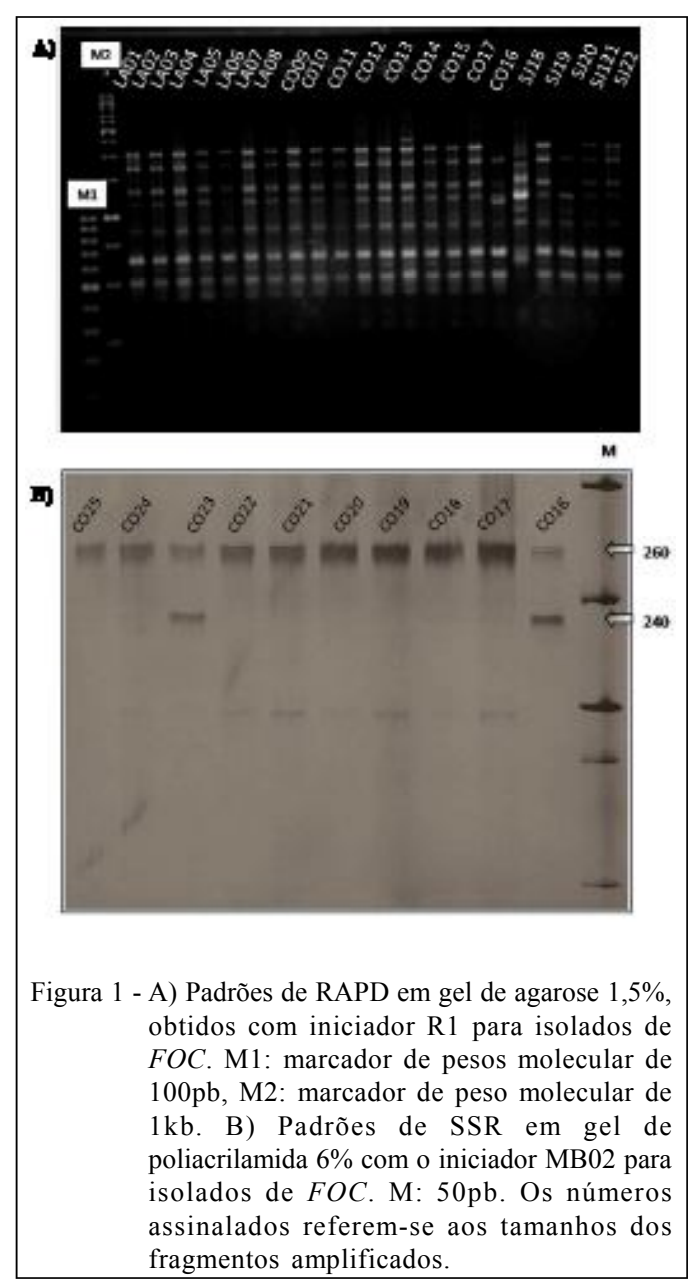




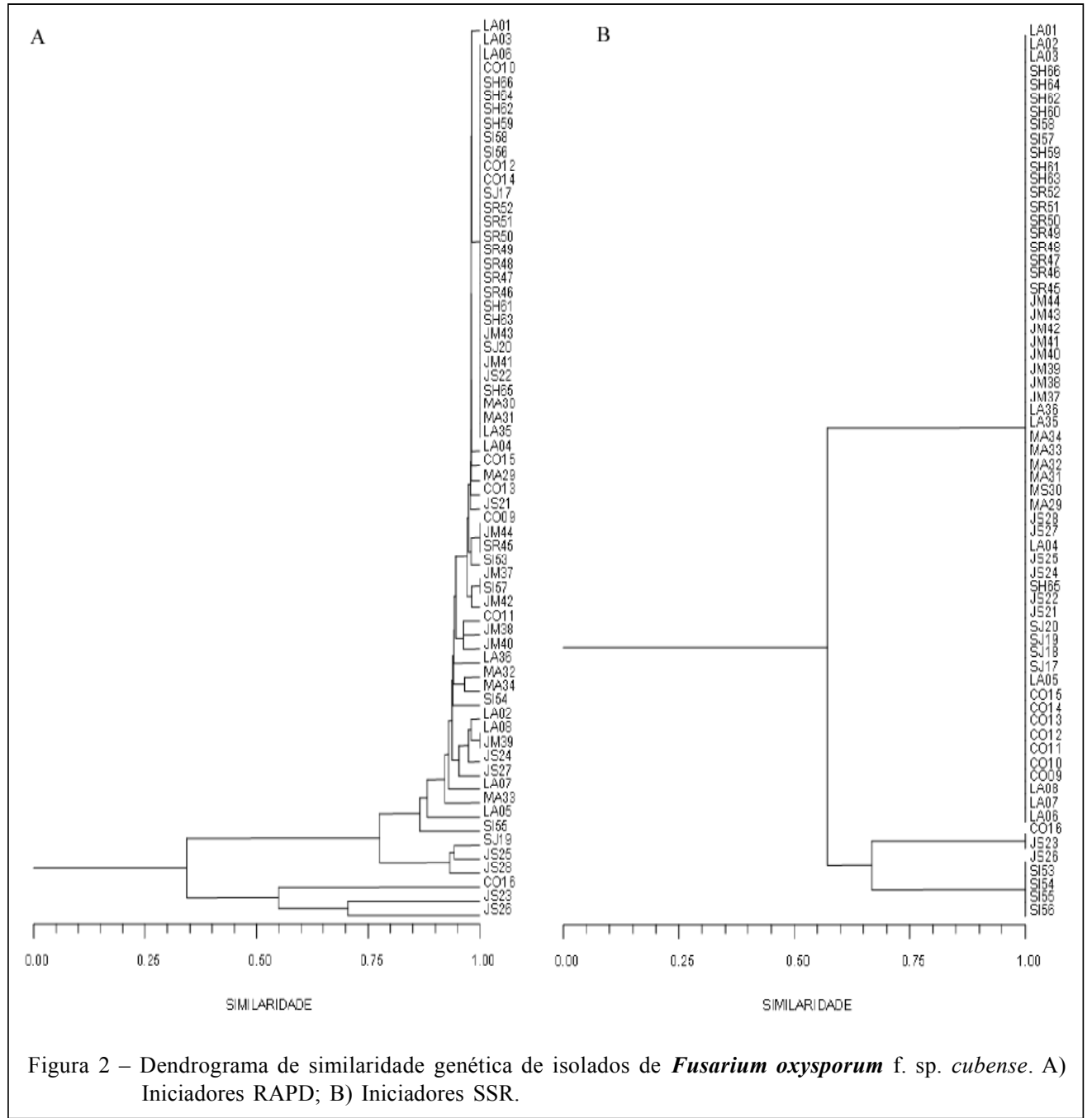

técnica com potencial para estudar a dinâmica de população e evolução desse fungo.

Dos seis iniciadores SSR utilizados para a análise dos isolados, dois foram selecionados por exibirem padrões de amplificações definidos na literatura (BOGALE et al., 2005). O iniciador MB02 amplificou uma banda de tamanho $260 \mathrm{pb}$ em todos os isolados analisados e também uma banda de tamanho 240pb nos isolados CO16, SJ23, JS26, SI53, SI54, SI55, SI56. O iniciador MB11 amplificou uma única banda de tamanho $175 \mathrm{pb}$ em todos os isolados analisados, exceto CO16 e SJ23, nos quais não houve amplificação, sendo considerado alelo nulo (Figura 1B). A análise de conglomerados separou os isolados em três grupos distintos (Figura 2B). O primeiro grupo, com 57 indivíduos, teve $100 \%$ de similaridade interna. O segundo grupo, composto por dois isolados (CO16 e JS23), caracterizou-se por apresentar alelo nulo para o marcador MB11 e um alelo extra para o marcador MB02.
Já o terceiro grupo, formado por cinco isolados (JS26, SI53, SI54, SI55, SI56), caracterizou-se por apresentar um alelo extra no marcador MB02. O segundo e o terceiro grupo uniram-se em um nível de similaridade de $67 \%$, enquanto que este novo conglomerado uniu-se ao primeiro grupo em um nível de similaridade de 57\%.

A baixa variabilidade observada pode estar relacionada ao número de iniciadores utilizados, o que gerou um baixo polimorfismo. Embora o SSR seja usado com frequência em função da codominância, do bom grau de polimorfismo e da presença de loci específicos, esse marcador vem sendo pouco utilizado em estudos com fungos. Isso se deve ao fato de que a obtenção de um nível aceitável de polimorfismo é geralmente mais difícil em fungos do que em outros organismos (DUTECH et al., 2007).

Neste trabalho, foi obtido alelo nulo para o locus MB11, o que provavelmente se deveu a mutações na sequência de anelamento (DAKIN \& AVISE, 2004), 
já que este marcador foi desenvolvido especificamente para Fusarium oxysporum (BOGALE et al., 2005). A presença de alelos nulos em vários organismos é citada na literatura (BRONDANI et al., 2000; CRUZ et al., 2009; SANTOS et al., 2010) e, embora isso possa dificultar as análises, esses alelos não devem ser descartados, pois refletem uma nova fonte de variabilidade genética e podem ser usados na discriminação de indivíduos.

No lócus MB02, ocorreu um alelo extra em alguns dos isolados, alelo este que não era esperado, uma vez que o FOC é um organismo haplóide (BENTLEY et al., 1998). Essa ocorrência poderia ser explicada por um anelamento inespecífico durante a PCR ou pela própria duplicação do lócus no genoma (KISTLER et al., 1995). A amplificação de duas bandas para alguns indivíduos poderia também ter ocorrido em função de anastomose, ou seja, fusão de hifas que forma heterocários, conforme verificado por KISTLER (1997).

De acordo com a literatura, os microssatélites apresentam vantagens sobre o marcador RAPD, porque são codominantes e facilmente reproduzíveis. Além dessas características, os microssatélites parecem ter uma distribuição frequente e aleatória, permitindo assim uma ampla cobertura do genoma (LEHMANN et al., 1996). Neste estudo, verificou-se que a técnica RAPD também foi viável para detectar a variabilidade genética de $F O C$, pois, em ambas as metodologias, obteve-se a formação de um grande grupo com mais de $80 \%$ dos isolados originários dos diferentes municípios estudados. Devido aos isolados C016, JS23 e JS26, provenientes da Região Norte do Estado de Santa Catarina, apresentarem-se mais distantes geneticamente nos dendrogramas de similaridade, sugere-se estudo mais aprofundado futuramente com eles.

Como os históricos da bananicultura nas regiões Norte e Sul de Santa Catarina são diferenciados, procurou-se verificar se os níveis de variabilidade observados para as cepas de $F O C$ guardavam relação com essas duas regiões. No Sul do estado, os pomares são da cultivar 'Enxerto', do subgrupo 'Prata', enquanto que no Norte as cultivares 'Maçã' e 'Prata' foram substituídas pelas cultivares 'Nanica', 'Nanicão' e 'Grande Naine', do subgrupo Cavendish, em função de sua maior resistência ao mal-do-panamá. No entanto, a maior diversidade de hospedeiros na região norte não se refletiu em uma maior diversidade das cepas do fungo. Corroborando esse resultado, GROENEWALD et al. (2006) afirmam que os clones de FOC são estáveis, e mutações no genoma do patógeno não ocorrem com frequência, independentemente dos grupos genômicos do hospedeiro.
Este estudo, que foi um dos primeiros trabalhos no Sul do país a caracterizar molecularmente o fungo causador do mal-do-panamá, resultou em dados que poderão servir de subsídio aos trabalhos de seleção de materiais genéticos resistentes e estáveis.

\section{CONCLUSÃO}

As técnicas moleculares RAPD e SSR foram eficientes em separar os isolados de Fusarium oxysporum f. sp. cubense em grupos distintos, sendo que os membros de cada grupo, em cada uma das técnicas, em geral, foram coincidentes, e três dos isolados (CO16, JS23 e JS26) apresentaram-se mais distantes geneticamente nos dendrogramas de similaridade.

\section{AGRADECIMENTOS}

Trabalho realizado com auxílio financeiro da Embrapa (Convênio 10200.06/0239-5), da Fundação de Apoio à Pesquisa Científica e Tecnológica do Estado de Santa Catarina (FAPESC) (Convênio 14.210/2007-7), do MAPA (Convênio SFA-SC 003/2006) e da Associação dos Bananicultores de Santa Catarina.

\section{REFERÊNCIAS}

ASIF, MJ. et al. Study of resistance of Musa acuminata to Fusarium oxysporum using RAPD markers. Biologia Plantarum, v.48, p.93-99, 2004. Disponível em: <http:// www.springerlink.com/content/r10155507281187j>. Acesso em: 20 mar. 2010. doi: 10.1023/B:BIOP.0000024281.85427.6d.

BELABID, L. et al. Pathogenic and genetic characterization of Algerian isolates of Fusarium oxysporum f.sp. lentis by RAPD and AFLP analysis. American Journal of Biotechnology, v.3, p.25-31, 2004.

BENTLEY, S. et al. Genetic variation among vegetative compatibility groups of Fusarium oxysporum f.sp. cubense analyzed by DNA fingerprinting. Phytopathology, v.88, p.12831293, 1998. Disponível em: <http://apsjournals.apsnet.org/doi/ pdfplus/10.1094/PHYTO.1998.188.12.1283>. Acesso em: 15 out. 2009. doi: 10.1094/PHYTO.1998.88.12.1283.

BOGALE, M. et al. Simple sequence repeat markers for species in the Fusarium oxysporum complex. Molecular Ecology, v.5, p.622-624, 2005. Disponível em: <http://onlinelibrary.wiley.com/ doi/10.1111/j.1471-8286.2005.01015.x/abstract>. Acesso em: 02 fev. 2009. doi: 10.1111/j.1471-8286.2005.01015.x.

BRONDANI, C. et al. Development of microsatellite markers for the genetic analysis of Magnaporthe grisea. Genetics and Molecular Biology, v.23, p.753-762, 2000. Disponível em: $<$ http://www.scielo.br/scielo.php?pid=S 1415 47572000000400009\&script=sci_arttext $>$. Acesso em: 04 abr. 2010. doi: $10.1590 /$ S1415-47572000000400009.

BUSSO, C. et al. Vegetative compatibility and molecular characterization of Fusarium graminearum isolates from the State of Paraná, Brazil. Ciência Rural, v.37, p.1813-1816, 
2007. Disponível em: http://www.scielo.br/scielo.php?pid=S010384782007000600050 \&script $=$ sci arttext $>$. Acesso em: 03 mar. 2010. doi: $10.1590 / \mathrm{S} 0103-84782007000600050$.

CASTRO, N.R. et al. Ocorrência, métodos de inoculação e agressividade de Fusarium oxysporum f. sp. cubense em Heliconia spp. Summa Phytopathologica, v.34, p.127130, 2008. Disponível em: <http://www.scielo.br/ scielo.php? script=sci_arttext \& pid=S $0100-$ 54052008000200003>. Acesso em: 20 mar. 2009. doi: $10.1590 / \mathrm{S} 0100-54052008000200003$.

CORDEIRO, Z.J.M. et al. Doenças da bananeira (Musa spp.). Manual de fitopatologia, v.2, p.99-117, 2005.

CRUZ, M.F.A. et al. Caracterização genética e fenotípica de Pyricularia grisea do trigo. Tropical Plant Pathology, v.34, p.393-401, 2009. Disponível em: <http://www.scielo.br/ scielo.php?script=sci_arttext\&pid=S 1982 56762009000600005>. Acesso em: 05 abr. 2010. doi: $10.1590 / \mathrm{S} 1982-56762009000600005$.

DAKIN, E.E.; AVISE, J.C. Microsatellite null alleles in parentage analysis. Heredity, v.93, 504-509, 2004. Disponível em: $<$ http://www.nature.com/hdy/journal/v93/n5/full/ 6800545a.html>. Acesso em: 20 maio, 2010. doi:10.1038/ sj.hdy. 6800545 .

DUTECH, C. et al. Challenges of microsatellite isolation in fungi. Fungal Genetics and Biology, v.44, p.933-949, 2007. Disponível em: <http://www.ese.u-sud.fr/bases/upresa/pages/ giraud/pdfs/Dutech2007pdf>. Acesso em: 10 mar. 2009. doi:10.1016/j.fgb.2007.05.003.

GROENEWALD, S. et al. The application of high-throughput, AFLPs in assessing genetic diversity in Fusarium oxysporum f.sp. cubense. Mycological Research, v.110, p.297-305, 2006. Disponível em: <http://dx.doi.org/10.1016/j.mycres.2005.10.004>. Acesso em: 05 nov. 2009. doi:10.1016/j.mycres.2005.10.004.

KISTLER, H.C. et al. Genetic duplication in Fusarium oxysporum. Current Genetics, v.28, p.173-176, 1995. Disponível em: $<$ http://www.springerlink.com/content/w2634q25882p1256/>. Acesso em 10 dez. 2009. doi: 10.1007/BF00315784.

KISTLER, H.C. Genetic diversity in the plant - Pathogenic fungus Fusarium oxysporum. Phytopathology, v.87, p.474479, 1997. Disponível em : <http://apsjournals.apsnet.org/doi/ pdf/10.1094/PHYTO.1997.87.4.474>. Acesso em: 15 out. 2009. doi: 10.1094/PHYTO.1997.87.4.474.

KOPP, M.M. Métodos de visualização de DNA. In: ZIMMER P.D. et al. Ferramentas da biotecnologia do melhoramento genético vegetal. Pelotas, RS: Editora Gráfica Universitária, 2005. Cap 5, p.115-156.

KUMAR, B.H. et al. Genetic variation in Fusarium oxysporum f.sp. cubense isolates based on random amplified polymorphic DNA and intergenic spacer. Archives of Phytopathology and Plant Protection, v.39, p.151-160, 2006. Disponível em: $<\mathrm{http}: / /$ www.informaworld.com/smpp/ content $\sim \mathrm{db}=\mathrm{all} \sim \mathrm{content}=\mathrm{a} 745983287>$. Acesso em: $04 \mathrm{fev}$. 2009. doi: $10.1080 / 03235400500319903$.

KURAMAE, E.E.; SOUZA, N.L. Variabilidade genética entre formas speciales de Fusarium oxysporum e raças 1 e 2 de Fusarium oxysporum f. sp. lycopersici através de RAPD e sequências de regiões ITS e rDNA. Acta Scientiarum, v.24, p.1481-1485, 2002. Disponível em: <http://periodicos.uem.br/ ojs/index.php/ActaSciAgron/article/view/2409/1808>. Acesso em: 08 mar. 2009.

LEHMANN, T. et al. An Evaluation of evolutionary constraints on microssatelite loci using null alleles. Genetics Society of America, v.144, p.1155-1163, 1996. Disponível em: <http:/ /www.ncbi.nlm.nih.gov/pmc/articles/PMC1207608/pdf/ ge14431155.pdf>. Acesso em: 03 mar. 2010.

MARTINS, M.K. Variabilidade genética de isolados de Fusarium spp. e estudo da interação com a planta hospedeira. 2005. 110f. Tese (Doutorado em Agronomia) Escola Superior de Agricultura "Luiz de Queiroz", Universidade de São Paulo, SP.

MOSTAFA, M. et al. Use of RAPD, enzyme activity staining, and colony size to differentiate phytopathogenic Fusarium oxysporum isolates from Iran. Journal of Microbiology, v.33, p.299-303, 2002. Disponível em: $<$ http://www.scielo.br/scielo.php?pid=S1517$83822002000400004 \&$ script=sci_arttext $>$. Acesso em: $03 \mathrm{fev}$. 2009. doi: $10.1590 / \mathrm{S} 1517-83822002000400004$.

NELSON, P.E. et al. Fusarium Species. An illustrated manual for indentification. United States of America: The Pennsylvania State University, 1983. 193p.

PARK, J.M. et al. Comparison of RAPD, AFLP, and EF-1a sequences for the phylogenetic analysis of Fusarium oxysporum and its formae specialis in Korea. Mycobiology, v.34, p.45$55,2006$.

PLOETZ, R.C. Fusarium wilt of banana is caused by several pathogens referred to as Fusarium oxysporum f. sp. cubense. Phytopathology, v.96, p.653-656, 2006. Disponível em: $<$ http://apsjournals.apsnet.org/doi/pdf/10.1094/PHYTO-960648>. Acesso em: 06 fev. 2009. doi: 10.1094/PHYTO-960648 .

ROHLF, F.J. NTSYS - pc: Numerical taxonomy and multivariate analysis system. (Version 2.1). New York: Exeter Publishing, 2001. CD.

SANTOS, C.A. et al. Caracterização molecular de cultivares de cebola com marcadores microssatélites. Pesquisa Agropecuária Brasileira, v.45, p.49-55, 2010. Disponível em: <http:// webnotes.sct.embrapa.br/pab/pab.nsf/FrAutor>. Acesso em: 07 maio, 2010

SCOTT, R.P. et al. A procedure for mini-scale preparation of Pyricularia grisea DNA. International Rice Research Notes, v.8, p.47-48, 1993.

SUTTON, J.C. Strategies for biological control of necrotrophic pathogens in perennial crops. Fitopatologia Brasileira, v.25, p.235-238, 2000.

VAKALOUNAKIS, D.J.; FRAGKIADAKIS G.A. Genetic diversity of Fusarium oxysporum isolates from cucumber: differentiation by pathogenicity, vegetative compatibility, and RAPD fingerprinting. American Phytopathological Society, v.89, p.161-169, 1999. Disponível em: <http://apsjournals.apsnet.org/ doi/pdf/10.1094/PHYTO.1999.89.2.161>. Acesso em: 03 fev. 2009. doi: 10.1094/PHYTO.1999.89.2.161.

VENTURA, J.A.; HINZ, R.H. Controle das doenças da bananeira. In: ZAMBOLIM, L. et al. Controle de doenças de plantas Fruteiras. Viçosa: Suprema, 2002. V.2, p.839-937.

Ciência Rural, v.40, n.12, dez 2010. 